\title{
CT- ANGIOGRAPHY BASED STUDY OF VARIATIONS IN BRANCHING
} PATTERN OF RENAL ARTERY

\section{Bali Sharma ${ }^{1}$, Dhiraj Saxena ${ }^{2}$, Shweta Asthana *3.}

${ }^{1}$ Assistant professor, Department of Anatomy, SMBT Medical college, Nashik, Maharashtra, India.

2 Professor, Department of Anatomy, S.M.S. Medical college Jaipur, Rajasthan, India.

${ }^{* 3}$ Assistant professor, Department of Anatomy, RNT Medical College Udaipur, Rajasthan, India.

\section{ABSTRACT}

Objective: The purpose of the present study is to search and detailed the existence and occurrence of anatomical variations of the renal artery by using CT angiography.

Materials and Methods: 100 patients visited the Radiology department of S.M.S. Medical College, Jaipur. To cover the whole abdominal aorta in each patient, spiral CT angiography scan was made and thin slices (0.6 $\mathrm{mm}$ ) axial images was obtained. Both sagittal and coronal images were reconstructed.

Results: We found that only $23 \%$ patients had classical (Normal) anatomical presentation of Renal artery, whereas in $77 \%$ patients, variations existed in the same, using CT angiography method.

Conclusion: The different varieties of renal vessels have been experienced with expanding recurrence over past decade. This is because of wide spread utilization of renal angiography and other imaging modalities, as of late. We as anatomist accept that anatomical information on atypical renal courses is significant for all careful and radiological intercessions including the kidneys or it might prompt mistaken translation.

KEY WORDS: Vessels, Renal Artery, Angiography, variations.

Corresponding Author: Dr. Shweta Asthana, Assistant professor, Department of Anatomy, RNT Medical College Udaipur, Rajasthan, India. E-Mail: dr.shweta.asthana@gmail.com

Access this Article online

Quick Response code

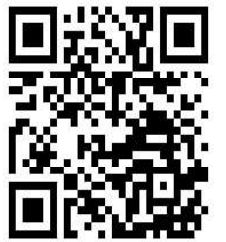

DOI: $10.16965 /$ ijar.2020.226

Journal Information

\section{International Journal of Anatomy and Research}

ISSN (E) 2321-4287 | ISSN (P) 2321-8967

https://www.ijmhr.org/ijar.htm

DOI-Prefix: https://dx.doi.org/10.16965/ijar

\section{Article Information}

Received: 23 Sep 2020

Peer Review: 23 Sep 2020

Revised: 25 Sep 2020
Accepted: 13 Nov 2020

Published (O): 05 Dec 2020

Published (P): 05 Dec 2020

\section{INTRODUCTION}

Typically, aorta provides a solitary renal artery on both side which supplies separate kidneys. The kidneys are one of the essential organs in the human body. It gets rich blood amount, almost $25 \%$ of the cardiovascular yield go through the renal courses to be cleaned by the kidneys. Typical life systems depict every kidney gets water system from single renal supply route which emerges from stomach aorta at the level L1-L2 vertebrae just beneath the artery of midgut.

Variations of renal arteries incorporate their source, number, and course; the most wellknown is the presence of extra vessels (frill supply routes) emerging over the typical trunk is more regular than one emerging underneath. Variation veins have been called extra, additional, abnormal, or superfluous branches [1]. The extra renal courses are consistently end supply routes. The kidneys may get a solitary conduit albeit every organ may similarly be provided by upwards of six end vessels. The renal supply routes may emerge from the aorta by a typical stem or emerge at lower point than expected in which 
case the kidneys lie beneath their standard position. There might be a many renal supply routes on each side or the renal course may split up near its root into various branches. They do not show anastomosis. The structure of renal vessels assumes a significant function in choosing contributors. 3-D angiotomography is the best methodology for vascular anatomic assessment.

Current Literature reports incredible inconstancy in renal blood flow, the quantity of renal supply routes referenced being the most habitually discovered variety. It is most basic renovascular oddity, found in $25 \%-50 \%$ of kidneys. One or two extra renal courses are normally found, particularly on the left side. They generally puncture the upper or lower part of the organ, despite taking entry at its hilum [2]. The varieties portrayed in the current perception present an exceptional example of intrinsic renal vascular variations having sectional and radiological significance.

\section{MATERIALS AND METHODS}

The study was conducted in Department of Anatomy in collaboration with Department of Radiology, SMS Medical College \& Hospital, Jaipur (Rajasthan). CT angiography was randomly selected from the records of patients visited the radiology department of S.M.S. Medical College, Jaipur. To cover the whole abdominal aorta in each patient, spiral CT angiography scan was made, and thin slices $(0.6 \mathrm{~mm})$ axial images were obtained. Both sagittal and coronal images were reconstructed. 3-D reconstruction was done from the data gained by the spiral CT examination. Manipulation of the 3-D images was done by rotation to get the correct planes and deletion of unnecessary anatomical details to clarify the renal artery away from superimposed structures. Data was saved into DVDs.

- Inclusion criteria: Subjects, who were free of any signs \& symptoms related to kidney arterial pathology.

Exlusion criteria: Subjects who have- Hydronephrosis, Renal calculi, Arterial pathology such as aneurysm or tumours.

\section{RESULTS}

Study was conducted on total 100 patients, it is found that 23 patients i.e. $23 \%$, were having normal branching pattern (fig.1.1) , 25 patients i.e. $25 \%$ presence of accessory renal artery (fig.1.2, 1.2A,1.2B,1.2C), there is presence of extrapolar branches in 20 patients i.e. $20 \%$ (fig.1.3,1.3A ,1.3B), presence of prehilar branches in 15 patients i.e. $15 \%$ (fig1.4), 10 patients having aberrant renal arteries i.e.10\% (fig1.5) and 7 patients having double renal arteries i.e. 7\% (fig1.6).

There are number of variations are observed in branching pattern of renal arteries (according to present study).

Type I Pattern was observed in 23 cases only i.e. $23 \%$, in which right \&left renal arteries arise from abdominal aorta near the hilum of kidney it divides in to anterior \& post division (fig.1.1).

Type II Pattern was observed in 25 cases i.e.25 $\%$, in which accessory renal artery arises and supplies the kidney with renal artery (fig.1.2, 1.2A, 1,2B, 1.2C).

Type III Data was observed in 20 cases i.e. 20\%, in that type presence of extrapolar branch of renal artery, it supply either superior or inferior pole known as superior or inferior polar arteries (fig.1.3,1.3A,1,3B).

Type IV Branching pattern was observed in 15 cases i.e. $15 \%$, in that case presence of prehilar branches which arise from renal artery before entering the kidney (fig1.4).

Type V Pattern was observed in 10 cases i.e.10\%. In this case an artery arises from renal arteries takes different path to supplying the kidney known as aberrant renal artery (fig 1.5).

Type VI Pattern was observed in 7 cases i.e. $7 \%$ in this case kidney not supplied by single artery. It is supplied by double renal artery (fig 1.6).

Table 1: Branching pattern of renal artery in males and females according angiography.

\begin{tabular}{ccccccc}
\hline $\begin{array}{c}\text { BRANCHING } \\
\text { PATTERN }\end{array}$ & \multicolumn{2}{c}{ MALE } & \multicolumn{2}{c}{ FEMALE } & \multicolumn{2}{c}{ TOTAL } \\
\hline Type I & 17 & 28.34 & 6 & 15 & 23 & 23 \\
\hline Type II & 15 & 25 & 10 & 25 & 25 & 25 \\
\hline Type III & 11 & 18.34 & 9 & 22.5 & 20 & 20 \\
Type IV & 8 & 13.34 & 7 & 17.5 & 15 & 15 \\
Type V & 6 & 10 & 4 & 10 & 10 & 10 \\
Type VI & 3 & 5 & 4 & 10 & 7 & 7 \\
\hline Total & 60 & 100 & 40 & 100 & 100 & 100 \\
\hline
\end{tabular}




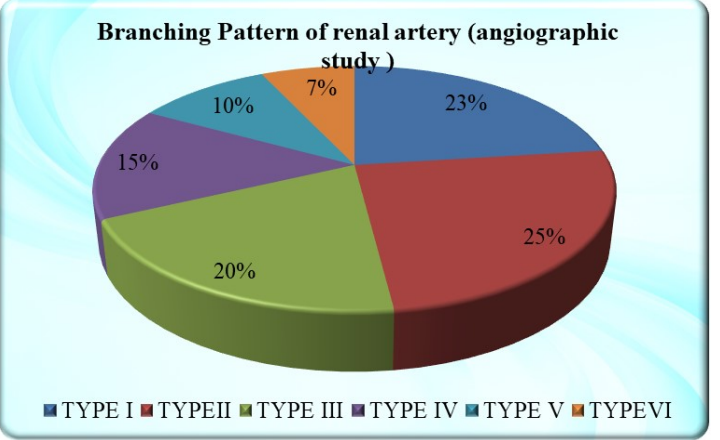

The branching pattern of renal artery according to angiographical data divides in to following types as under:

Type I - Normal

Type II - Presence of accessory renal artery Unilateral Bilateral

Type III- Presence of extra Polar branch Superior polar Lower polar

Type IV -Presence of prehilar branches Type V -Presence of aberrant renal artery Type VI -Presence of double renal artery

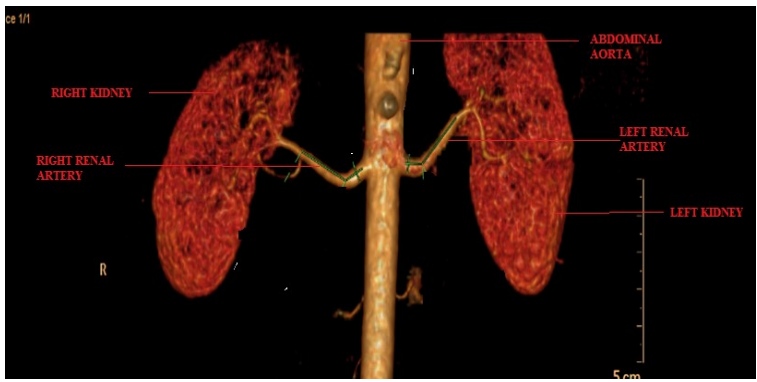

Fig. 1.1: TYPE I Normal branching pattern of renal artery

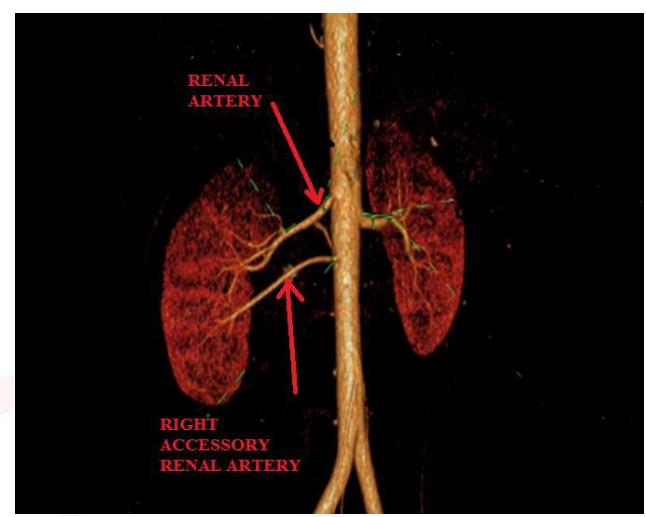

Fig. 1.2: TYPE II- (A) Presence of unilateral (right) accessory renal artery

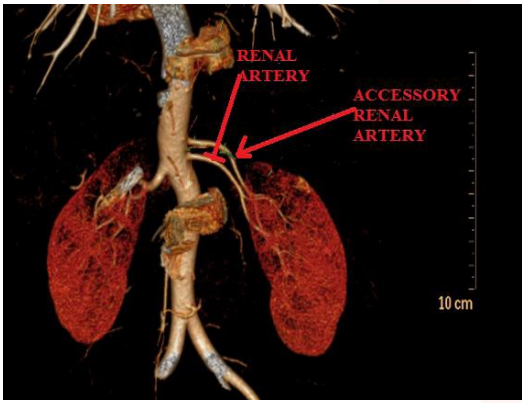

Figure 1.2: TYPE II (B) Presence of unilateral (left) accessory renal artery

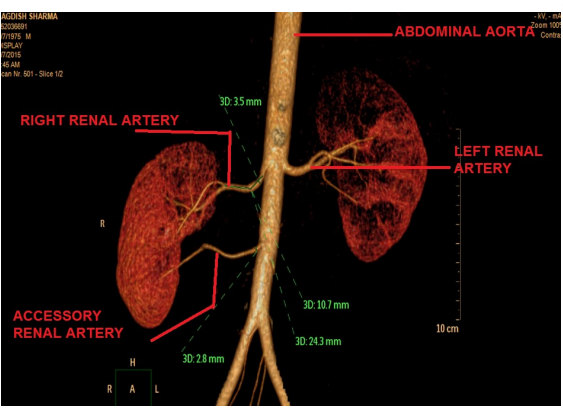

Figure 1.3: TYPE III (B) Presence of extra polar branch (inferior polar)

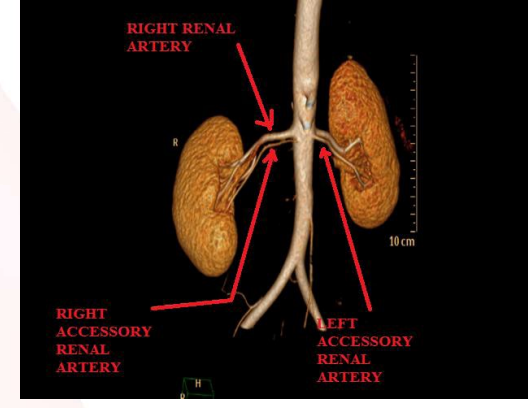

Figure 1.2: TYPE II (C) Presence of bilateral accessory renal artery.

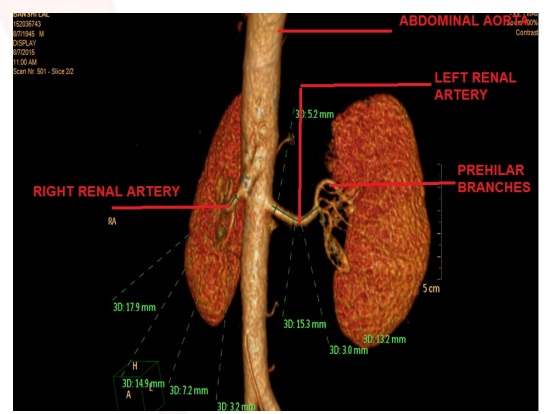

Fig. 1.4: TYPE IV Presence of prehilar branches.

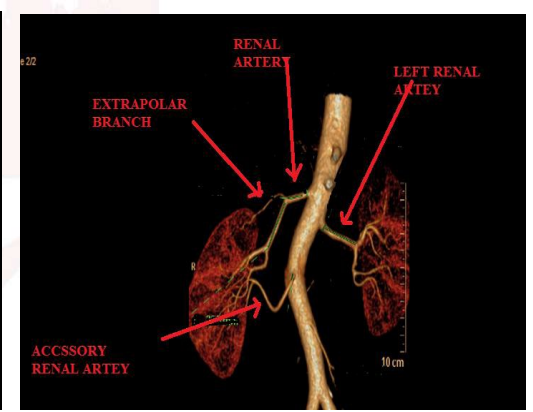

Figure 1.3: TYPE III(A) Presence of extra polar branch (superior polar).

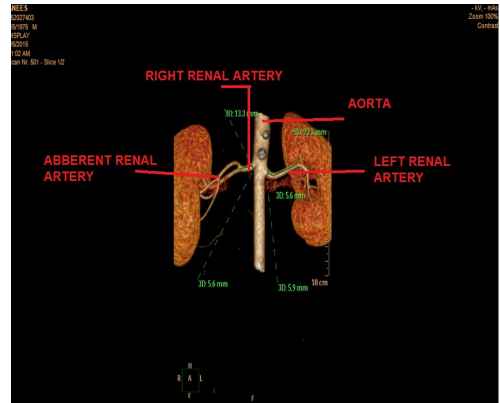

Fig. 1.5: TYPE V Presence of aberrant renal artery.

Figure 1.6: TYPE VI- Presence of double renal artery.
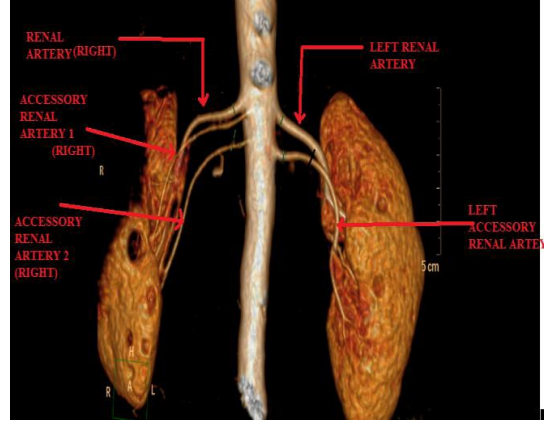
Table 1.2: A comparative incidence of number of renal artery in different population.

\begin{tabular}{lccccc}
\hline \multicolumn{1}{c}{ Author (year) } & Population & Type of study & $\begin{array}{c}\text { Single } \\
\text { (\%) }\end{array}$ & $\begin{array}{c}\text { Double } \\
\text { (\%) }\end{array}$ & $\begin{array}{c}\text { Triple } \\
\text { (\%) }\end{array}$ \\
\hline Khamanarong et al (2004) [4] & Thai & CTA & 82 & 17 & 1 \\
Ozkan et al(2006) [5] & Turkish & Conventional Angio & 76 & 13.5 & 0.9 \\
Raman et al(2007) [6] & American & 64 slice CTA & 81 & 15.9 & 3.6 \\
\hline Tarzmani et al (2008) [7] & Iranian & 64 slice CTA & 74.4 & 22.6 & 2.1 \\
\hline Saldarriaga et al (2008) [8] & Colombian & Cadaveric & 77.8 & 20.1 & 2.1 \\
Ogeno et al(2010) [9] & Kenyan & Cadaveric & 71.8 & 24.8 & 2.6 \\
Anshu Mishra et al (2014) [10] & Indian & 64 slice CTA & 67.92 & 26.4 & 5.66 \\
Present study (2019) & Indian & 64 slice CTA & 75 & 25 & 0 \\
\hline
\end{tabular}

The research work was undertaken and find out morphological variation related with renal artery with the help of CT angiography.

Gollamandala Syamala et. al. [3] observed that Distribution divides into various types. Some kidneys supplied by main renal artery with extra renal artery. Some renal arteries divide before entering into the kidney. Some extra renal arteries enter through upper or lower pole of kidney.

In the present angio-graphical study have find $25 \%$ (accessory renal artery) on either side. Out of 100 pair renal arteries, $75 \%$ of kidneys were irrigated by single renal artery, $25 \%$ by two renal arteries (accessory renal arteries) and we have not found any case of three renal arteries. Present study found that $8 \%$ left side, $12 \%$ right side and $5 \%$ bilaterally.

In the present study there are number of variations found in case of distribution of blood supply of kidneys. $23 \%$ cases there is presence of normal renal artery .25\% cases kidneys are supplied accessory renal arteries. In angiography, $20 \%$ of cases show superior and inferior polar arteries. $15 \%$ cases showing presence of prehilar branches. We observed that aberrant renal arteries are found in $10 \%$ cases and $7 \%$ cases are showing presence of double renal arteries (Table-1). These observations comparable with Govindarajan A (2014)[11], Dr. Chandrika(2012)[12], Virendra Budhiraja (2013) [13].

Most of the variations of human renal vessels can be explained on the basis of phylogeny. An anomalous in human, is normally present in some animals. The most common variation of renal artery is an accessory renal artery arising from aorta or main renal artery about $30 \%[14]$.

The possible etiology of these variations has been explained by embryological development from the lateral mesonephric branches of the dorsal aorta [15].

Kishor B et. al. [16] quoted that variations of renal arteries were important in vascular reconstructions and surgical procedures.

\section{CONCLUSION}

CT Angiography Based Study on variations in branching pattern of renal arteries with surgical correlation was undertaken in the department of Anatomy in collaboration with Department of Radiology. The various variations of renal arteries have been encountered with increasing frequency over past decade. This is due to wide spread use of renal angiography and other imaging modalities, in recent years. We as anatomist believe that anatomical knowledge of anomalous renal arteries is important for all surgical and radiological interventions involving the kidneys or it may lead to erroneous interpretation.

\section{Conflicts of Interests: None}

\section{REFERENCES}

[1]. Standring S. Gray's Anatomy; The Anatomical Basis of Clinical Practice 40th ed. Edinburg: Churchill and Livingstone, 2008:1231-1233.

[2]. Merklin RJ, Michel NA. The variant renal and suprarenal blood supply with data on the inferior phrenic, ureteral and gonadal arteries. J Int Coll Surg 1958;29:41-76.

[3]. Gollamandala Syamala.Morphology and Variations of Renal Artery Pattern: A Case Report, IOSR Journal of Dental and Medical Sciences, 2015;14(4):2931. 
[4]. Khamanarong, K., Prachaney, P., Utaravichien, A., Tong-Un, T. and Sripaoraya, K. 2004. Anatomy of renal arterial supply, Clin Anat, 17: 334-6. Khamanarong, K., Prachaney, P., Utaravichien, A., Tong-Un, T. and Sripaoraya, K. Anatomy of renal arterial supply, Clin Anat, 2004;17:334-6.

https://doi.org/10.1002/ca.10236

PMid:15108340

[5]. Ozkan, U., Oguzkurt, L., Tercan, F., Kizilkiliç, O., Koç, Z. and Koca, N. 2006 Renal artery origins and variations: angiographing evaluation of 855 consecutive patients. Diagn Interv Radiol, 2006;12:183-6.

[6]. Raman S.S. Pojchamarnwipath S.M. and Mvangsom boon K. Surgically relevant Normal and variant Renal Parenchymal and vascular Anatomy in Preoperative 16-MDCT Evaluation of potential Laparoscopic Renal Donors. AJR, 2007;188:105-14. https://doi.org/10.2214/AJR.05.1002 PMid:17179352

[7]. Tarzamni MK, Nezami N, Rashid RJ, Argani H, Hajealioghli P, Ghorashi S. Anatomical differences in the right and left renal arterial patterns. Folia Morphol, 2008;67(2):104-10.

[8]. Saldarriaga B. Pinto S.A. and Ballesteros L.E. Morphological expression of the renal artery. A direct Anatomical study in a Colombian half-caste population. Int J Morphol, 2008;26:31-38.

https://doi.org/10.4067/S0717-95022008000100005

[9]. Ogeno J.A. Masaki C.O. Sinkeet S.R. Muthoka J.M. and Murunga A.K. Variant anatomy of renal arteries in a Kenyan population. Ann Transplant, 2010;15(1):40-45.

[10]. Mishra Anshu, Sharma P K, Manik Punita, Singh Ragini, Singh S K et., Variation in Number and Vertebral Level of Origin of Renal Artery in North Indian Population, J. Biol. Chem. Res., 2014;31(1):182-191.

[11]. Govindarajan A, Meenakshisundaram J. Right ectopic kidney with rare vascular variations. International Journal of Anatomical Variations. 2011;4(1)12-14.
[12]. Dr Chandrika G Teli, Ushakothandaraman; Complex and unusual variation of renal vessels embryologicbasis and clinical significance; IJAV;2012:5: 87-89.

[13]. Virendra Budhiraja, Rakhi Rastogi, Vaibhav Anjankar, C.S. Ramesh Babu, Prabhat Goel. Research article "Supernumerary Renal arteries \& their embryological \& Clinical correlation, A Cadaveric study from North India. Hindawi Publishing Corporation ISRN Anatomy;2013 (Article ID-405712) https:// doi.org/10.5402/2013/405712 PMid:25938099 PMCid:PMC4392953

[14]. Gupta A, Gupta R, Singhla RK. The Accessory Renal Arteries: A Comparative Study in Vertebrates with Its Clinical Implications. J Clin Diagn Res 2011;5:9703.

[15]. Satyapal KS, Haffejee AA, Singh B, Ramsaroop L, Robbs JV, Kalideen JM. "Additional renal arteries: incidence and morphometry. Sur. Radiol. Anat. 2001; 23 (1): 33-38. https://doi.org/10.1007/s00276-001-0033-y PMid:11370140

[16]. Kishor Bhandari. Study on Variation in the Origin of Renal Artery, IOSR Journal of Dental and Medical Science, 2014;13(2): 55-57. https://doi.org/10.9790/0853-13235557

\author{
How to cite this article: \\ Bali Sharma, Dhiraj Saxena, Shweta Asthana. CT- ANGIOGRAPHY \\ BASED STUDY OF VARIATIONS IN BRANCHING PATTERN OF \\ RENAL ARTERY. Int J Anat Res 2020;8(4.2):7805-7809. DOI: \\ 10.16965/ijar.2020.226
}

